\title{
THE CIRCULAR ECONOMY PACKAGE OF THE EUROPEAN UNION: ARE NEW PATHS BEING TAKEN OR IS IT AN OLD STORY?
}

\section{Andreas Bartl}

TU Wien - Institute of Chemical, Environmental and Bioscience Engineering, Getreidemarkt 9, 1060 Wien, Austia

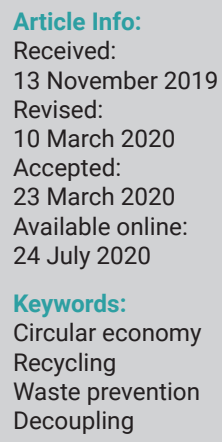

\section{ABSTRACT}

The European Commission is in the process of improving its waste management and as a result, the so-called Circular Economy Package (CEP) has been launched. As a matter of fact, only recently several directives in the field of waste management have been amended and in the next years targets for re-use and recycling of waste will be significantly tightened. However, the CEP aims to go beyond recycling and issues such as easy-to-repair design or new business models are put in the foreground. It is striking that some ideas of the CEP are already more than four decades old. Nevertheless, the CEP has to be welcomed under the motto "better late than not at all".

\section{INTRODUCTION}

In the European Union, waste management has changed dramatically in recent years (Pomberger, Sarc, \& Lorber, 2017). In the year 1995 , only $25 \cdot 10^{3} \mathrm{t}$ of municipal solid waste (MSW) have been recycled in the EU which corresponded to about $11 \%$ of the total quantity of $227 \cdot 103 t$ (eurostat, 2019). The most current dataset of 2017 shows that the total amount of MSW increased by $10 \%$ to $249 \cdot 10^{3}$ $\mathrm{t}$ but the amount of recycled waste has almost quadrupled $\left(115 \cdot 10^{3} \mathrm{t}\right)$ which means that the recycling rate is as high as $46 \%$ (eurostat, 2019).

In order to further promote recycling and waste prevention the European commission has presented a so-called circular economy package (European Commission, 2015). The intention is not only to save the environment but to create new jobs, boost the economy and reduce the dependency on scarce resources. The project seems almost ingenious as the interests of environmental, the economic and social aspects can be aligned. The question is whether the plan is realistic or whether it is not worth the paper it is written on.

\section{THE CIRCULAR ECONOMY}

\subsection{The genesis of the circular economy}

Circular Economy is a concept that has spread virally in recent years. Based on a search in the database SciFinder ${ }^{\circledR}$ (ACS, 2019) the term is quite new as its first evidence in the scientific literature was not before 2003 (Xue et al., 2003). In the "early stage" circular economy was dominated by China. In the period from 2003 to 2007 SciFinder ${ }^{\circledR}$ reports 29 entries of which 26 are in Chinese language (ACS, 2019). The only paper in English including a Digital Object Identifier (DOI) was published in 2007 (Peters et al., 2007), but it also deals with China. Basically, Circular Economy seems to be a Chinese "invention".

The first paper on Waste Prevention as important goal in modern waste management has already been mentioned much earlier in 1906 (Phelps, 1906) followed by Resource Management in 1965 (Fitzpatrick \& Heller, 1965) and Zero Waste in 1975 (Milios, 1975; Wang \& Yang, 1975) according to SciFinder ${ }^{\circledR}$.

The chart in Figure 1 shows that in 2008 the terms Circular Economy (19 entries), Zero Waste (18 entries) and Waste Prevention (5 entries) lag far behind Resource Management (212 entries). In the last decade the usage of Circular Economy tremendously increased, in particular since the year 2015. As a result, in the year 2018 the usage of Resource Management (503 entries) and Circular Economy (443 entries) is almost equal. In the year 2019 (on the reporting date 13 November 2019) Circular Economy could take the lead with 662 entries over Resource Management with 479 entries. Even though Circular Economy was a latecomer, the term has become indispensable in today's waste management. 


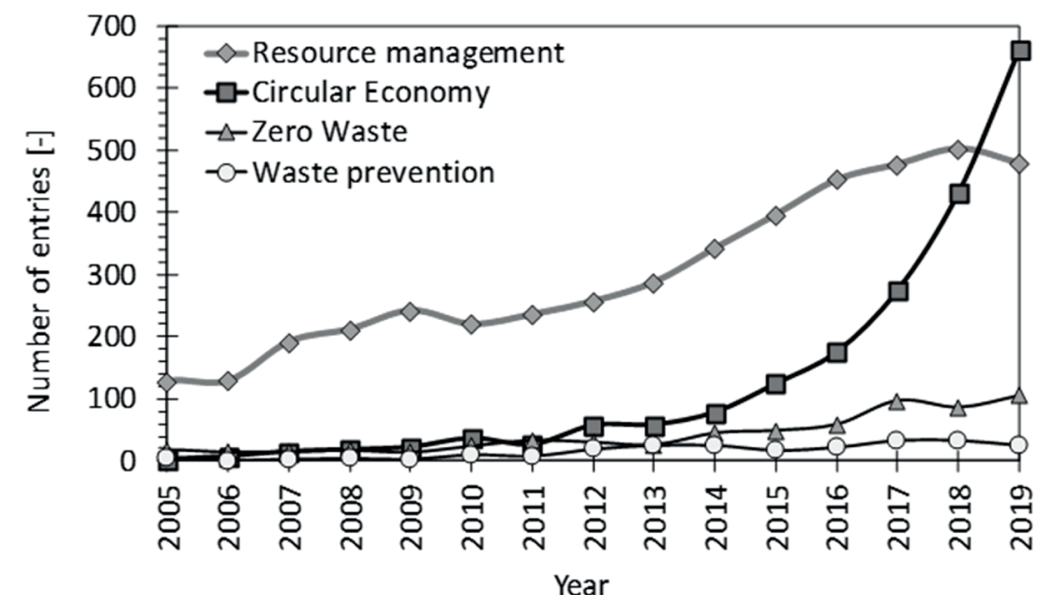

FIGURE 1: Number of entries in the database SciFinder ${ }^{\circledR}$ for the research topic "Resource Management", "Circular Economy", "Zero Waste" and "Waste Prevention" between 2005 and 2019; the entries of 2019 are based on the reporting date 13 November 2019.

\subsection{The EU perspective on the circular economy}

It was not until the 1970's before sound waste management became an issue in the European Union. As a reaction on environmental problems associated with waste disposal the first directive on waste was enacted in 1975 (European Communities, 1975). It was amended in 1991 (European Communities, 1991), 1996 (European Communities, 1996) and 2006 (European Parliament, 2006) and replaced by the Waste Framework Directive (WFD) in 2008 (European Parliament, 2008). The WFD introduced the waste hierarchy with waste prevention as upmost goal.

On 2 July 2014 the European Commission presented a proposal to amend some directives in the field of waste management (European Commission, 2014). Later, on 16 December 2014 the proposal was withdrawn by the new Commission (FUSIONS, 2014) and replaced by a new, "even more ambitious", suggestion which was released on 2 December 2015 (European Commission, 2015). Finally, the Directive (EU) 2018/851 (European Parliament, 2018a) has been passed in 2018 amending the WFD. As a matter of fact the "circular economy" must be implemented in all EU member states by 2020 .

\subsection{The issue of growth}

It is the goal of most governments to create framework conditions that enable a high growth of the economy. Economists claim that the gross domestic product (GDP) should show a growth ideally between 2 and $3 \%$ (Amadeo, 2019). Below or above this interval, economy is not healthy and problems will occur.

Our current economic system is dependent on growth. As shown by Strunz and Schindler (2018) there exist barriers to reach a post-growth economy. In particular, the authors investigated the following case studies:

- Economic growth is essential to keep unemployment on a low level. Up to now policies of reducing working time to translating only future productivity gains into leisure have not be successful.

- Alternative indicators to GDP have not succeeded in replacing GDP even if alternative measures such as "green GDP" are available (Stjepanović et al. 2017). Only recently the disadvantages of the indicator GDP have been clearly demonstrated (Brynjolfsson \& Collis, 2019; Kapoor \& Debroy, 2019).

- Pension systems depend on economic growth to compensate for demographic change. In an elaborate study Alda (2017) shows that population growth is essential that pension funds show a positive effect on stock markets independent on the age of the population.

The growth and the doubling rate are logarithmically related and the doubling rate can be calculated by the formulae shown in Equation 1 and Equation 2. This relationship is further demonstrated in Figure 2. Even though a growth of 2 or $3 \%$ seems quite moderate it means that the doubling time is 23 or 35 year, respectively.

The situation is further outlined in Figure 3. Starting at a value of 1 (e.g. GDP, population, waste generation, etc.) an exponential growth occurs. After a period of 50 years, which lies within the time frame of human life, the value has increased 2.7 times (2\% growth) or 4.4 times (3\% growth). The situation is worse when considering a growth rate of $5 \%$ which means that after 50 years the starting value has increased 11.5 times. Compared to China a growth of $5 \%$ is very moderate as its economy has shown an even higher increase (IMF, 2019). Figure 4 plots the growth rates of China's GDP (from 2011 to forecasts until 2023) which averages at $6.88 \%$. A growth of $6.88 \%$ means a doubling time of 10.4 years only (Figure 2 ) and will result in a 28fold increase over 50 years (Figure 3 ). While many people will welcome such an economic growth, it is clear that a 28-fold generation of waste, GHG emissions or energy consumption is unacceptable for the environment.

$q=1+P / 100$

where:

q Growth rate [-]; P Growth [\%], e.g. GDP, waste, etc.

$t_{d}=\ln (2) / \ln (q)$

where:

$t_{d}$ Doubling time $[a]$ 
$v=q^{t}$

where:

v value [a.u.], e.g. GDP, waste, etc.; $t$ time [a]

A tree is a perennial plant which can reach considerable heights even up to $120 \mathrm{~m}$ (Koch et al., 2004). It is reported

(3) a Karri tree (Eucalyptus diversicolor) can grow quite fast and reaches a height up to $60 \mathrm{~m}$ after 60 years (Rayner, 1991). However, it will not grow up to the sky. The growth speed will significantly slow down and finally it will stop growing at an age of about 100 years (Rayner, 1991) even if it can get much older.

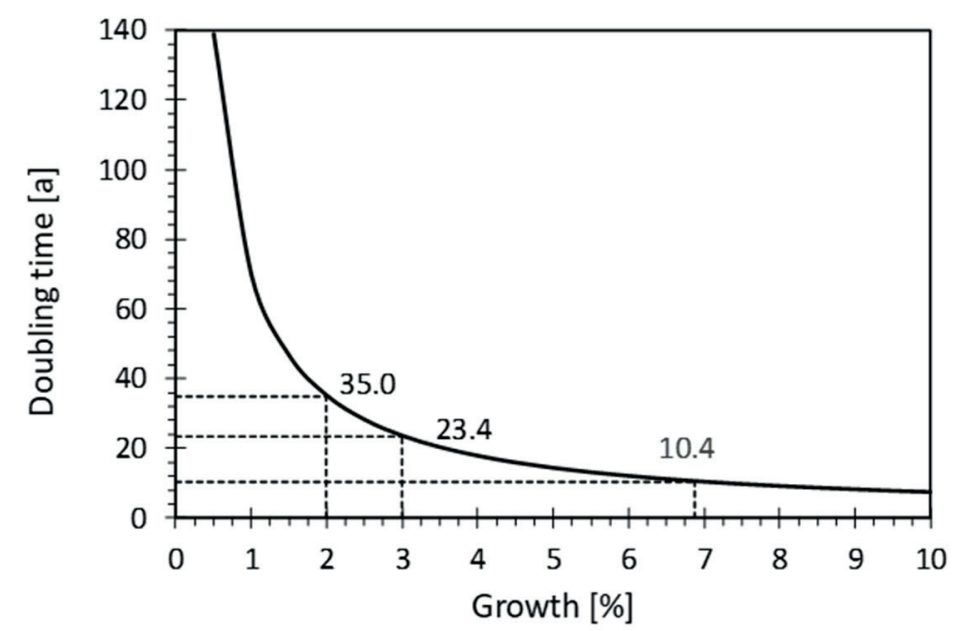

FIGURE 2: Doubling time as a function of growth (e.g. GDP, waste, GHG emissions, etc.) as calculated by Equation 1 and Equation 2.

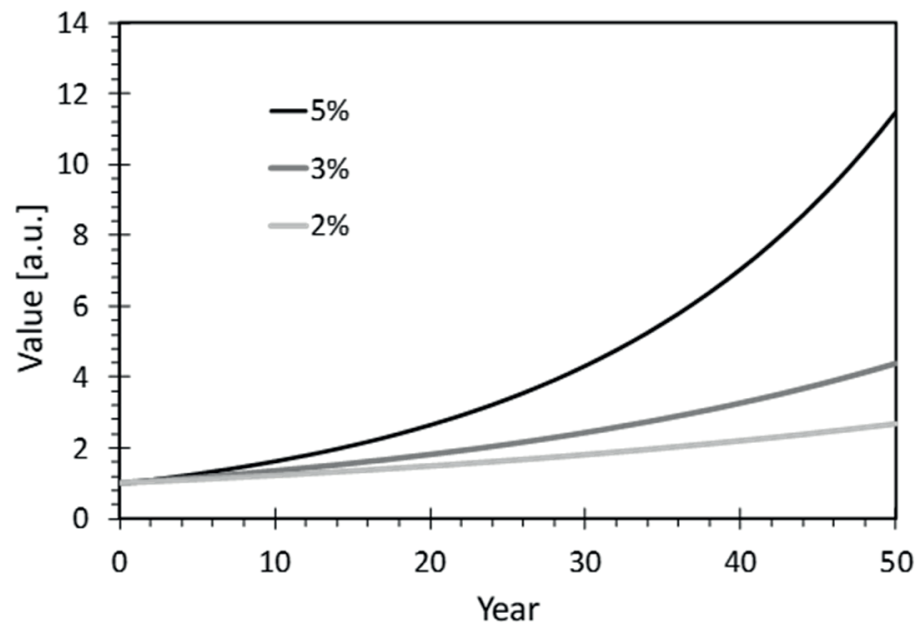

FIGURE 3: Exponential growth with 2, 3, 5 and $6.88 \%$ over 50 years; starting at 1 in the year 0 calculated according to Equation 3.

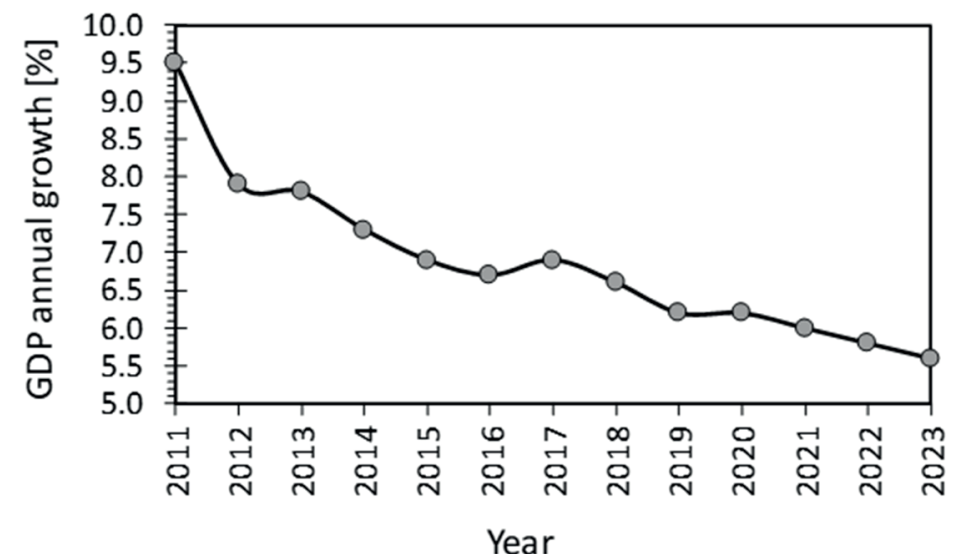

FIGURE 4: Annual growth rate of China's GDP from 2011 to 2017 and forecasts until 2023 (IMF, 2019). 
The question is justified, why our economy is condemned to always grow. A sustainable system will grow, but only to a certain point. As exemplarily shown for a tree, ecosystems on our globe move towards an equilibrium state.

\subsection{The limits to growth}

The problem of exponential growth (Figure 2) was already addressed in 1972 by the famous book "The Limits to Growth" (Meadows et al., 1972). The authors concluded that the limits to growth on earth would become evident by 2072 if business was continued as usual. Without appropriate measures, in 2072 a "sudden and uncontrollable decline in both population and industrial capacity will" (Meadows et al., 1972) occur. The authors demanded that economy and population must reach an equilibrium state and any growth must be prohibited. Basically, the growth of population and economy must follow the example of a tree which stops growth at a certain height.

\section{CIRCULAR ECONOMY PACKAGE VS. THE LIMITS TO GROWTH}

It is striking that some of the key points of the circular economy package are already anticipated in "The Limits to Growth". Meadows et al. (1972) mention in Chapter "V The State of Global Equilibrium" some examples of technological advance that are required even if an equilibrium state (i.e. no growth of population or economy) is achieved.

A. "new methods of waste collection, to decrease pollution and make discarded material available for recycling"

B. "more efficient techniques of recycling, to reduce rates of resource depletion"

C. "better product design to increase product lifetime and promote easy repair, so that the capital depreciation rate would be minimized"

The sentence (A) sounds very current. Indeed, in Chapter 3. "Waste management" of the Circular Economy Package (European Commission, 2015) the importance of waste collection as an enabler for recycling is pointed out:

- [...] The way we collect and manage our waste can lead either to high rates of recycling and to valuable materials finding their way back into the economy, or to an inefficient system where most recyclable waste ends in landfills or is incinerated, with potentially harmful environmental impacts and significant economic losses. [...]

The importance of waste collection is further emphasized in the new Directive (EU) 2018/852 (European Parliament, 2018b), which was enacted as a results of the CEP and is amending the Directive 94/62/EC (European Parliament, 1994) on packaging and packaging waste. The revised directive introduces stringent targets for re-use and recycling packaging waste. However, in the introduction in paragraph 20 and and in the revised article 7 under paragraph 1(a) one can find the following sentences:

- [...] Effective extended producer responsibility schemes can have a positive environmental impact by reducing the generation of packaging waste and increasing its separate collection and recycling [...].

- [...] the return and/or collection of used packaging and/ or packaging waste from the consumer, other final user, or from the waste stream in order to channel it to the most appropriate waste management alternatives [...].

The ideas of Meadows et al. (Meadows et al., 1972) and the Directive (EU) 2018/851 (European Parliament, 2018) are strikingly similar as both define waste collection as a key element for recycling. In 1972 the separate collection of waste was still in its infancy and it was not clear what "new methods of waste collection" will be. The "new methods of waste collection" have not yet been known, but today in many countries extended produced responsibility (EPR) is the core of legislation and policy to deal with end-of-life products, in particular packaging (Gupt \& Sahay, 2015). EPR is the main driver for a separate collection of waste and seems to be the "new method" as demanded by Meadows et al. (1972). However, in many EU countries even today separate collection and recycling is on a very low level. In 5 EU countries, Malta, Greece, Cyprus, Croatia and Romania, more than $70 \%$ of municipal waste is disposed of (landfilling or incineration D10). It seems that the proposals of Meadows et al. (Meadows et al., 1972) have gone unheard for four decades.

Also suggestion (B) can be found in the Circular Economy Package (European Commission, 2015) in a quite similar way. In chapter 4 - From waste to resources: boosting the market for secondary raw materials and water reuse, 1 st paragraph and in chater 6 - Innovation, investment, and other horizontal measures, $2^{\text {nd }}$ paragraph one can read:

- In a circular economy, materials that can be recycled are injected back into the economy as new raw materials thus increasing the security of supply;

- We will need new technologies, processes, services and business models.

The message of both is quite similar. Recycling is assigned an important role and it is the key element to reduce the demand for primary resources. According to Meadows et al. (Meadows et al., 1972) the main reason for recycling is the environment and the reduction of the depletion of limited resources. In contrast, the CEP sees the advantage of recycling in securing the supply of raw materials and boosting the economy (European Commission, 2015).

Finally, suggestion (C) can be found in a similar way in the CEP (European Commission, 2015) in Chapter 1.1 - Product design, first paragraph, in Chapter 2 - Consumption $5^{\text {th }}$ paragraph and 1 Chapter 5.3. - Critical raw materials, $2^{\text {nd }}$ paragraph:

- Better design can make products more durable or easier to repair;

- Once a product has been purchased, its lifetime can be extended through reuse and repair, hence avoiding wastage;

Improve the recyclability of electronic devices through product design. 
The above-mentioned principles represent the core of the CEP. It is not about targets for re-use and recycling but it addresses the minimization of the quantity of waste. It is striking that the ideas are more than 40 years old, but still today there are no appropriate measures to get waste prevention off the ground. In contrast, products such as electronic devices or apparel are getting increasingly cheaper. The useful life is more and more reduced and, even worse, items are becoming disposable goods. It has to be welcomed that the EU commission has addressed the right targets but it has to be questioned how our society can get there. Producers and retailers are interested to increase sales and turnaround. Policies such as a long service life or easy-to-repair design are often a mere lip service and do not take place in practice.

\section{CONCLUSIONS}

The CEP (European Commission, 2015) does indeed seem to be an "old hat". Some of the most important elements were formulated more than four decades ago by Meadows et al. (1972). Nonetheless, the CEP is still up to date because there is still a lack of substantial and consistent implementation of these ideas. In particular, the proposals of the CEP that go beyond the mere fixing of quotas are to be welcomed.

However, it is not clearly stated in the CEP how some of these requirements can be implemented in practice. Even if an increase of product lifetime and an easy-to-repair design are very efficient measures to reduce waste, manufacturers and retailers will continue to increase the sales. However, it is the first step in the right direction and it is to be hoped that the time is now ripe to put the concepts of waste prevention into practice.

Even though the concepts of the CEP (European Commission, 2015) and "the limits to growth" (Meadows et al., 1972) are similar to a certain extent, a clear difference is discernible. According to Meadows et al. (1972) it is absolutely necessary to achieve an equilibrium state in which growth has come to a standstill which is, in particular, outlined for population and economy. However, the European commission sees the CEP as a tool to boost the European economy and increase growth. According to Meadows et al. economic growth would wipe out all technological advances.

\section{REFERENCES}

ACS, (2019), SciFinder®. American Chemical Society. Retrieved from https://scifinder.cas.org/scifinder/view/scifinder/scifinderExplore.jsf.

Alda, M. (2017), The relationship between pension funds and the stock market: Does the aging population of Europe affect it? International Review of Financial Analysis, 49, 83-97, doi: https://doi. org/10.1016/j.irfa.2016.12.008.

Amadeo, K. (2019), What Is the Ideal GDP Growth Rate? Retrieved from https://www.thebalance.com/what-is-the-ideal-gdp-growthrate-3306017 [9 March 2020].

Brynjolfsson, E. \& Collis, A. (2019), How Should We Measure the Digital Economy? Harvard Business Review, Nov-Dec, Retrieved from: https://hbr.org/2019/11/how-should-we-measure-the-digitaleconomy [9 March 2020].

European Commission (2014), Communication from the Commission to the European Parliament, the Council, the European Economic and Social Committee and the Committee of the Regions, Towards a circular economy: A zero waste programme for Europe (2014), $\operatorname{COM}(2014) 398$ final.
European Commission (2015), Communication from the Commission to the European Parliament, the Council, the European Economic and Social Committee and the Committee of the regions, Closing the loop -An EU action plan for the Circular Economy, COM(2015) 614 final.

European Communities (1975), Council Directive 75/442/EEC of 15 July 1975 on waste. Official Journal of the European Union, 18(L194), 39-41.

European Communities (1991), Council Directive 91/156/EEC of 18 March 1991 amending Directive 75/442/EEC on waste Official Journal of the European Union, 34(L78), 32-37.

European Communities (1996), 96/350/EC: Commission Decision of 24 May 1996 adapting Annexes IIA and IIB to Council Directive $75 / 442 / E E C$ on waste. Official Journal of the European Union, 39(L135), 32-34.

European Parliament, (1994), European Parliament and Council Directive 94/62/EC of 20 December 1994 on packaging and packaging waste. Official Journal of the European Union, 37(L365), 10-23.

European Parliament, (2006), Directive 2006/12/EC of the European Parliament and of the Council of 5 April 2006 on waste. 49(L114), 9-21.

European Parliament (2008), Directive 2008/98/EC of the European Parliament and of the Council of 19 November 2008 on waste and repealing certain Directives Official Journal of the European Union, 51(L312), 3-30.

European Parliament (2018a), Directive (EU) 2018/851 of the European Parliament and of the Council of 30 May 2018 amending Directive 2008/98/EC on waste. Official Journal of the European Union, 61(L150), 109-140.

European Parliament (2018b), Directive (EU) 2018/852 of the European Parliament and of the Council of 30 May 2018 amending Directive $94 / 62 / E C$ on packaging and packaging waste. Official Journal of the European Union, 61(L150), 141-154.

eurostat (2019), Municipal waste by waste management operations. Retrieved from http://appsso.eurostat.ec.europa.eu/nui/submitViewTableAction.do.

Fitzpatrick, J. V., \& Heller, A. N. (1965), A Dynamic Air Resource Management Program, City of Chicago. Journal of the Air Pollution Control Association, 15(7), 297-301. Retrieved from https://doi.or $\mathrm{g} / 10.1080 / 00022470.1965 .10468381$. doi:10.1080/00022470.19 65.10468381.

FUSIONS (2014), EC's Circular economy package to be re-tabled in 2015. Retrieved from https://www.eu-fusions.org/index.php/14news/26-ec-s-circular-economy-package-to-be-re-tabled-in-2015 [9 March 2020].

Gupt, Y. \& Sahay, S. (2015), Review of extended producer responsibility: A case study approach. Waste Management \& Research, 33(7), 595- 611. doi: 10.1177/0734242X15592275.

IMF (2019), China: growth rate of real gross domestic product (GDP) from 2011 to 2023. Statista - The Statistics Portal. Retrieved from https://www.statista.com/statistics/263616/gross-domesticproduct-gdp-growth-rate-in-china/ [9 March 2020].

Kapoor, A. \& Debroy, B. (2019), GDP Is Not a Measure of Human Well-Being. Harvard Business Review, Sep-Oct, Retrieved from: https://hbr.org/2019/10/gdp-is-not-a-measure-of-human-well-being [9 March 2020].

Koch, G. W., Sillett, S. C., Jennings, G. M., \& Davis, S. D. (2004), The limits to tree height. Nature, 428(6985), 851-854. Retrieved from https://doi.org/10.1038/nature02417. doi: 10.1038/nature02417.

Meadows, D. H., Meadows, D. L., Randers, J., \& Behrens III, W. W. (1972), The Limits to growth: A report for the Club of Rome's Project on the Predicament of Mankind. New York: Universe Books.

Milios, P. (1975), Water reuse at a coal gasification plant. Chemical Engineering Progress, 71(6), 99-104.

Peters, G. P., Weber, C. L., Guan, D., \& Hubacek, K. (2007), China's Growing CO2 EmissionsA Race between Increasing Consumption and Efficiency Gains. Environmental Science \& Technology, 41(17), 5939-5944. Retrieved from https://doi.org/10.1021/es070108f. doi:10.1021/es070108f.

Phelps, E. B. (1906), The prevention of stream pollution by strawboard waste (189). Retrieved from http://pubs.er.usgs.gov/publication/ wsp189

Pomberger, R., Sarc, R., \& Lorber, K. E. (2017), Dynamic visualisation of municipal waste management performance in the EU using Ternary Diagram method. Waste Management, 61, 558-571, doi: https:// doi.org/10.1016/j.wasman.2017.01.018.

Strunz, S. \& Schindler, H. (2018), Identifying Barriers Toward a Postgrowth Economy - A Political Economy View. Ecological Economics, 153, 68-77, doi: https://doi.org/j.ecolecon.2018.06.017. 
Stjepanović, S., Tomić, D. \& Škare, M. (2017), A new approach to measuring green GDP: a cross-country analysis, Entrepreneurship and Sustainability Issues 4(4), 574-590. doi: https://doi.org/10.9770/ jesi.2017.4.4(13)

Rayner, M. E. (1991), Site index and dominant height growth curves for regrowth karri (Eucalyptus diversicolor F. Muell.) in south-western Australia. Forest Ecology and Management, 44(2), 261-283. doi: https://doi.org/10.1016/0378-1127(91)90013-L
Rugaber, J. W. (1953), Milk losses in dairy plants. Canadian Dairy and Ice Cream Journal, 32(6), 48,62.

Wang, L. K., \& Yang, J. Y. (1975), Total waste recycle system for water purification plant using alum as primary coagulant. Resource Recovery and Conservation, 1(1), 67-84. Retrieved from doi: https:// doi.org/10.1016/0304-3967(75)90015-3

Xue, D. F., Luo, H., \& Zhou, Z. (2003), Ecological planning of Nanhai eco-industrial park. 23, 285-288. 